\title{
Prevalensi Karies dan Erosi pada Narapidana Pengguna Narkotika Jenis Sabu-Sabu di Lembaga Pemasyarakatan Klas II-A Kabupaten Jember
}

(The Prevalence of Caries and Erosion in Methamphetamine Abuse Prisoner in The Prison Of Jember)

\author{
Syeifira Salsabila ${ }^{1}$, Hestieyonini Hadnyanawati ${ }^{2}$, Erawati Wulandari ${ }^{3}$ \\ 1 Fakultas Kedokteran Gigi, Universitas Jember \\ 2 Bagian Ilmu Kesehatan Gigi Masyarakat,Fakultas Kedokteran Gigi, Universitas Jember \\ 3 Bagian Konservasi Gigi, Fakultas Kedokteran Gigi, Universitas Jember
}

\section{Abstrak}

Masalah penyalahgunaan sabu-sabu di Indonesia masih sangat memprihatinkan meskipun larangan mengonsumsi narkotika di luar indikasi medis telah diatur dalam undang-undang. Pengguna sabu-sabu berisiko tinggi untuk terkena kerusakan gigi, kerusakan gigi yang sering terjadi pada pengguna sabu-sabu adalah karies dan erosi. Hal tersebut dikarenakan penyalahgunaan sabu-sabu dapat mempengaruhi kebersihan rongga mulut dan kualitas saliva para penggunanya. Mengingat tingginya risiko pengguna sabu-sabu untuk terkena karies dan erosi maka peneliti perlu melakukan penelitian yang bertujuan untuk mengetahui prevalensi karies dan erosi, serta mendeskripsikan karakteristik narapidana pengguna narkotika jenis sabu-sabu di Lembaga Pemasyarakatan Klas II-A Kabupaten Jember. Terdapat 58 responden dalam penelitian ini. Pengukuran karies dilakukan dengan menggunakan indeks DMF-T, pengukuran erosi dilakukan dengan menggunakan Basic Erosive Wear Examination, sedangkan karakteristik responden diperoleh melalui lembar kuisioner. Hasilnya prevalensi karies pada pengguna sabu-sabu adalah sebesar $89,66 \%$ dengan rerata skor DMF-T 7,21 dan prevalensi erosi adalah sebesar $72,41 \%$ dengan rerata skor erosi 5,29. Dapat disimpulkan bahwa 52ebagian besar pengguna sabu-sabu memiliki masalah karies dan erosi pada gigi geliginya.

Kata kunci: erosi, karies, sabu-sabu

\section{Abstract}

The problem of methamphetamine abuse in Indonesia is still very concerning even though the prohibition on consuming narcotics outside of medical indications has been regulated in law. Methamphetamine users are at high risk for tooth decay, tooth decay that often occurs in methamphetamine users is caries and erosion. This is because the abuse of methamphetamine can affect the oral hygiene and saliva quality of the users. Given the high risk of methamphetamine users being exposed to caries and erosion, researchers need to conduct research that aims to determine the prevalence of caries and erosion, as well as describe the characteristics of inmates who use shabushabu narcotics in the Class II-A Penitentiary Office Jember. There are 58 respondents in this study. Caries measurement was carried out using the DMF-T index, erosion measurement was carried out using the Basic Erosive Wear Examination, while the characteristics of the respondents were obtained through a questionnaire sheet. The result is that the prevalence of caries in methamphetamine users is $89.66 \%$ with a mean DMF-T score of 7.21 and the prevalence of erosion is $72.41 \%$ with a mean erosion score of 5.29 . It can be concluded that most users of methamphetamine have caries and erosion problems in their teeth.

Key words: caries, erosion, methamphetamine

Korespondensi (Correspondence) : Syeifira Salsabila, Jl. Kalimantan No.37, Kampus Tegalboto, Jember 68121, Indonesia, (0331) 330224, E-mail: syeifirasalsabilasisi@yahoo.com

Masalah penyalahgunaan narkotika di Indonesia masih sangat memprihatinkan meski larangan mengonsumsi narkotika di luar indikasi medis telah diatur dalam undangundang. Badan Narkotika Nasional memperoleh data bahwa dalam 1 semester di tahun 2018 terdapat 426 kasus narkotika jenis sabu-sabu dari total 540 kasus dengan temuan barang bukti sebanyak 676.522 gram sabusabu.'

Dampak berbahaya dari penyalahgunaan narkotika dapat timbul dari segi fisik maupun psikis, tak terkecuali rusaknya gigi geligi. Regina (2013) meneliti skor DMF-T pengguna sabu-sabu di Lembaga Pemasyarakatan Yogyakarta. ${ }^{2}$ Hasilnya 45, 10\% pengguna sabu-sabu memeiliki skor DMF-T sangat tinggi. Rommel dkk. (2016) meneliti efek simpatomimetik sabu-sabu pada pecandu sabu-sabu kronis. Penelitian tersebut menunjukkan $70 \%$ kelompok yang mengonsumsi sabu-sabu memiliki kualitas saliva yang buruk dibandingkan dengan kelompok yang tidak mengonsumsi sabu-sabu, sehingga pengguna sabu-sabu berisiko terkena erosi pada gigi geliginya. ${ }^{3}$

Lembaga Pemasyarakatan (Lapas) Klas II-A Kabupaten Jember merupakan tempat untuk melakukan pembinaan terhadap narapidana dan anak didik pemasyarakatan di Kabupaten Jember. Wawancara dengan petugas di Lapas Kabupaten Jember memperoleh informasi bahwa 123 dari 153 narapidana merupakan penyalahguna sabusabu. Lapas Kabupaten Jember belum pernah melakukan screening kesehatan gigi geligi narapidana, padahal screening berguna sebagai diagnosis dini dan identifikasi penyakit pada pasien yang berisiko, termasuk pecandu sabu-sabu yang memiliki risiko kerusakan gigi geligi lebih tinggi. ${ }^{4}$

Masalah kesehatan rongga mulut pecandu sabu-sabu belum banyak mendapat perhatian di Indonesia, termasuk di Lapas 
Kabupaten Jember. Mengingat tingginya risiko pecandu sabu-sabu untuk mengalami kerusakan gigi berupa karies dan erosi, perlu dilakukan penelitian untuk menggambarkan prevalensi karies dan erosi pada gigi geligi pengguna narkotika jenis sabu-sabu. Tujuan dilakukannya penelitian ini yaitu untuk mengetahui prevalensi karies dan erosi, serta mendeskripsikan karakteristik narapidana pengguna narkotika jenis sabu-sabu di Lembaga Pemasyarakatan Klas II-A Kabupaten Jember

\section{METODE PENELITIAN}

Penelitian ini merupakan jenis penelitian observasional deskriptif dengan pendekatan cross sectional. Penelitian dilakukan pada bulan Desember 2019 di Lembaga Pemasyarakatan Klas II-A Kabupaten Jember. Penelitian telah mendapat perizinan dari Fakultas Kedokteran Gigi Universitas Jember, Kantor Wilayah Kementerian Hukum dan HAM Surabaya, dan Lembaga Pemasyarakatan Klas II-A Kabupaten Jember.

Pengukuran karies dilakukan dengan menggunakan Indeks DMF-T menurut WHO (1986)5, pengukuran erosi menggunakan Basic Erosive Wear Examination menurut Bartlett dkk. $(2008)^{6}$, dan karakteristik narapidana didapatkan dari lembar kuisioner. Populasi penelitian ini yaitu 131 narapidana pengguna sabu-sabu di Lapas Klas II-A Kabupaten Jember. Penelitian menggunkan teknik pengumpulan data purposive sampling karena menggunakan kriteria sampel yaitu lama konsumsi sabu-sabu minimal 18 bulan dan tidak memiliki penyakit sistemik, sehingga didapatkan jumlah sampel yang memenuhi kriteria sejumlah 58 responden. Alat dan bahan yang digunakan dalam penelitian ini antara lain dental kit disposable, cotton pellet, petridish, handscoon, masker, headlamp, lembar kuisioner, dan alat tulis. Penelitian dilakukan pada 28 dan 31 Desember 2019 dengan tim 9 orang mahasiswa Universitas Jember. Data responden diolah dengan teknik analisis univariat dengan melakukan tabulasi dalam progam Microsoft Excel 2016. Persentase dan distribusi frekuensi didapatkan dari rumus prevalensi.

Jumlah kasus penyakit yang ada Total populasi $\times 100 \%$

\section{HASIL}

\section{Karakteristik Pengguna Sabu-sabu}

Hasil perolehan data dari kuisioner (Tabel 1) menunjukkan bahwa sebagian besar narapidana berjenis kelamin laki-laki $(86,20 \%)$ dan berada pada ketagori usia dewasa awal (26-35 tahun) (41,38\%). Tidak dijumpai narapidana yang tidak menyikat giginya, namun sebagian besar hanya menyikat gigi 1 kali sehari $(48,28 \%)$. Cara yang paling banyak digunakan narapidana untuk mengonsumsi sabu-sabu adalah menghisapnya (91,40\%). Rata-rata narapidana mengonsumsi sabu- sabu dengan frekuensi harian hingga mingguan $(68,97 \%)$ selama $\geq 4$ tahun $(82,76 \%)$.

Tabel 1. Karakteristik Narapidana Pengguna Sabu-sabu di Lembaga Pemasyarakatan Klas II-A Kabupaten Jember $(n=58)$

\begin{tabular}{|c|c|}
\hline Karakteristik & Jumlah Responden (\%) \\
\hline $\begin{array}{l}\text { Jenis Kelamin } \\
\text { Perempuan } \\
\text { Laki-laki }\end{array}$ & $\begin{array}{c}8(13,80) \\
50(86,20)\end{array}$ \\
\hline $\begin{array}{l}\text { Kategori Usia* } \\
\text { Remaja Akhir } \\
\text { Dewasa Awal } \\
\text { Dewasa Akhir } \\
\text { Lansia Awal }\end{array}$ & $\begin{array}{c}5(8,62) \\
24(41,38) \\
21(36,21) \\
8(13,79)\end{array}$ \\
\hline $\begin{array}{l}\text { Frekuensi Sikat Gigi } \\
\text { Tidak Pernah } \\
1 \text { kali } \\
2 \text { kali } \\
\text { Lebih dari } 2 \text { kali }\end{array}$ & $\begin{array}{c}0(0,00) \\
28(48,28) \\
14(24,14) \\
16(27,59)\end{array}$ \\
\hline $\begin{array}{l}\text { Cara Konsumsi } \\
\text { Dihisap } \\
\text { Dihirup } \\
\text { Disuntikkan } \\
\text { Ditelan } \\
\end{array}$ & $\begin{array}{c}53(91,40) \\
3(5,20 \\
2(3,40) \\
0(0,00)\end{array}$ \\
\hline $\begin{array}{l}\text { Frekuensi Konsumsi } \\
\text { Harian - Mingguan } \\
\text { Bulanan - Tahunan }\end{array}$ & $\begin{array}{l}40(68,97) \\
18(31,03)\end{array}$ \\
\hline $\begin{array}{l}\text { Lama Konsumsi } \\
<4 \text { tahun } \\
\geq 4 \text { tahun }\end{array}$ & $\begin{array}{l}10(17,24) \\
48(82,76)\end{array}$ \\
\hline $\begin{array}{l}\text { *Departemen Kesehata } \\
\text { Prevalensi Karies } \\
\text { Hasil pemeriks } \\
\text { bahwa komponen } \\
\text { dengan karies be } \\
\text { diketahui prevalensi } \\
\text { sabu sebesar } 89,66 \% \\
\text { pengguna sabu-sal } \\
\text { tergolong sangat ting }\end{array}$ & $\begin{array}{l}\text { Rl, 2009.7; \%, prosentase } \\
\text { dan klinis menunjukkan } \\
\text { D (Decay) atau gigi } \\
\text { rjumlah 323, sehingga } \\
\text { karies pengguna sabu- } \\
\text { (Tabel 2). Rerata DMF-T } \\
\text { ou adalah 7,21 yang } \\
\text { gi. }\end{array}$ \\
\hline
\end{tabular}

Tabel 2. Kategori DMF-T Narapidana Pengguna Sabu-sabu di Lembaga Pemasyarakatan Klas II-A Kabupaten Jember $(n=58)$

\begin{tabular}{lc}
\hline DMF-T & Jumlah Responden (\%) \\
\hline Komponen DMF-T & \\
D & $323(77,27)$ \\
M & $91(21,77)$ \\
F & $4(0,96)$ \\
\hline Total DMF-T & 418 \\
\hline Rerata & 7,21 \\
\hline Std. Deviasi & 5,48 \\
\hline
\end{tabular}

\section{Prevalensi Erosi}

Hasil penilaian skor erosi menunjukkan bahwa sebagian besar pengguna sabu-sabu memiliki skor erosi rendah $(60,34 \%)$ namun prevalensi erosinya sebesar dengan rerata skor erosi 5,29 yang tergolong rendah (Tabel 3). Diketahui 42 dari total 58 narapidana diketahui memiliki erosi dan membutuhkan perawatan 
(skor erosi kumulatif > 2), sehingga apabila diaplikasikan dalam rumus angka prevalensi maka didapatkan prevalensi erosi sebesar $72,41 \%$.

Tabel 3. Kategori Erosi Narapidana Pengguna Sabu-sabu di Lembaga Pemasyarakatan Klas II-A Kabupaten Jember

\begin{tabular}{lcc}
\hline Kategori Erosi & Frekuensi & $\mathbf{( \% )}$ \\
\hline Sangat Rendah & 16 & 27,60 \\
Rendah & 35 & 60,34 \\
Sedang & 6 & 10,34 \\
Berat & 1 & 1,72 \\
\hline Total & 58 & 100 \\
\hline Rerata & \multicolumn{3}{c}{5,29} \\
\hline Std. Deviasi & \multicolumn{3}{c}{3,19} \\
\hline
\end{tabular}

\section{PEMBAHASAN}

Penelitian ini memperoleh data yang menunjukkan bahwa rerata skor DMF-T pengguna sabu-sabu tergolong sangat tinggi (Tabel 2) dengan prevalensi karies sebesar $89,96 \%$. Tingginya rerata skor DMF-T tersebut berkaitan dengan penurunan laju aliran saliva yang diakibatkan aktivitas sabu-sabu pada saraf perifer, sehingga produksi saliva berkurang dan meningkatkan suasana asam dalam rongga mulut.8 Berkurangnya produksi saliva menyebabkan self cleansing dalam rongga mulut menjadi terganggu.? Selain itu pengguna sabu-sabu umumnya kurang memperhatikan kebersihan gigi dan mulutnya sehingga jumlah plak dan bakteri akan terus meningkat. Rongga mulut dengan suasana asam dan tidak terjaga kebersihannya akan meningkatkan risiko terjadinya karies, sehingga karies menjadi salah satu masalah kesehatan gigi yang banyak dijumpai pada pengguna sabu-sabu. 10 Karies yang ditemukan pada pengguna sabu-sabu timbul dengan proses yang lebih cepat dan terlihat lebih parah. Keparahan karies pada pengguna sabu-sabu disebabkan efek korosif sabu-sabu serta turunannya dapat terjadi secara lokal karena terekskresi melalui cairan krevikular gingiva. ${ }^{11}$

Penelitian terdahulu memperoleh data bahwa pengguna sabu-sabu memiliki kecenderungan 2 kali lebih besar untuk tidak merawat karies giginya, 4 kali lebih besar memiliki karies, dan 2 kali lebih besar memiliki gigi hilang karena karies. Rendahnya komponen $\mathrm{F}$ (Filling) atau gigi tumpatan pada narapidana pengguna sabu-sabu menunjukkan bahwa pengguna sabu-sabu cenderung kurang memperhatikan kesehatan rongga mulutnya. ${ }^{8}$ Penelitian lain menemukan bahwa $98,05 \%$ responden memiliki karies dengan rata-rata skor DMF-T 10 yang tergolong sangat tinggi. ${ }^{12}$

Pemeriksaan klinis yang telah dilakukan pada rongga mulut narapidana pengguna sabu-sabu, menunjukkan bahwa sebagian besar narapidana pengguna sabu-sabu memiliki skor erosi rendah (Tabel 3) dengan prevalensi erosi sebesar $72,42 \%$. Prevalensi erosi pada pengguna sabu-sabu tergolong tinggi, namun pada penelitian ini rata-rata skor erosinya rendah. Hal ini mungkin disebabkan kurang cermatnya peneliti pada saat melakukan pemeriksaan klinis, sehingga tidak tepat dalam menentukan skor erosi, selain itu mungkin terdapat perbedaan persepsi dalam menilai tingkat keparahan erosi antar tim peneliti. Sebagian besar narapidana diketahui mengonsumsi sabu-sabu dengan cara menghisap asap pembakaran sabu-sabu, hal ini menyebabkan sabu-sabu berkontak langsung dengan permukaan gigi sehingga meningkatkan risiko erosi gigi, namun demikian kontak asap sabu-sabu dengan permukaan gigi tidak berlangsung lama sehingga meskipun prevalensi erosi tinggi tetapi ratarata skor erosi rendah.

Sabu-sabu diketahui memiliki sifat korosif karena mengandung Hydrochloric acid dalam proses pembuatannya, sehingga gigi yang terpapar sabu-sabu dalam jangka panjang dapat mengalami erosi ${ }^{13}$. Faktor lain yang dapat menyebabkan erosi pada gigi geligi pengguna sabu-sabu adalah efek samping sabu-sabu yang dapat mengurangi laju aliran saliva dan $\mathrm{pH}$ saliva, padahal saliva merupakan proteksi yang berperan penting untuk melawan kerusakan struktur gigi melalui proses remineralisasi oleh kalsium yang terkandung di dalamnya. Laju aliran saliva dan $\mathrm{pH}$ saliva yang menurun mengakibatkan suasana rongga mulut menjadi asam sehingga meningkatkan risiko terjadinya erosi gigi. ${ }^{3}$

Penelitian sebelumnya tentang hubungan penggunaan sabu-sabu dengan peningkatan masalah kesehatan gigi dan mulut. Penelitian tersebut menemukan bahwa $72,80 \%$ pengguna sabu-sabu sedang memiliki masalah erosi pada gigi geliginya ${ }^{13}$. Penelitian lain tentang erosi gigi pada narapidana pengguna zat psikoaktif di Lembaga Pemasyarakatan (Lapas) Finlandia mengemukakan bahwa $90 \%$ narapidana memiliki gigi erosi dan membutuhkan upaya pencegahan dan perawatan. Riwayat gaya hidup narapidana pengguna sabu-sabu sebelum menjadi narapidana seperti pola makan yang tidak sehat, minum minuman beralkhohol, minuman bersoda, dan merokok merupakan faktor yang dapat mempengaruhi tingginya risiko erosi pada gigi geligi pengguna sabu-sabu. ${ }^{6}$

Kesimpulan yang diperoleh berdasarkan hasil penelitian yaitu prevalensi karies dan erosi pada narapidana pengguna sabu-sabu di lembaga Pemasyarakatn Klas II-A Kabupaten Jember tergolong tinggi yaitu masing-masing sebesar $89,66 \%$ dan $72,41 \%$. Sebagian besar pengguna sabu-sabu berjenis kelamin laki-laki, berusia 26-25 tahun, menyikat gigi 1 kali sehari, mengonsumsi sabu-sabu dengan cara dihisap dengan frekuensi harian hingga mingguan selama $\geq 4$ tahun. Keterbatasan penelitian ini yaitu tim meneliti masih awam dalam melakukan skoring erosi, sehingga terdapat kemungkinan adanya perbedaan persepsi antar tim peneliti dalam menentukan skor erosi responden. Sebaiknya dilakukan penelitian 
lebih lanjut tentang $\mathrm{pH}$ dan laju aliran saliva pada pengguna sabu-sabu terkait masalah kesehatan gigi geligi dengan jumlah sampel yang lebih sesuai untuk mewakili suatu populasi. Pemeriksaan klinis yang dilakukan untuk menilai skor erosi harus dilakukan dengan cermat agar didapatkan data yang lebih akurat.

\section{DAFTAR PUSTAKA}

1. Badan Narkotika Nasional Republik Indone-sia. Jurnal Data Narkoba Dalam Angka-Jurnal Data Puslitdatin BNN. Jakarta: Badan Narkotika Nasional. 2018.

2. Regina APVO. Tingkat Keparahan Karies Gigi pada Pengguna Metamfetamin di Lembaga Pemasyarakatan Narkotika Yogyakarta. Masters thesis. Yogyakarta: Universitas Gadjah Mada. 2013.

3. Rommel N, Rohleder NH, Koerdt $\mathrm{S}$, Wagenpfeil S, Härtel-Petri R, Wolff KD, dan Kesting MR. Sympathomimetic effects of chronic methamphetamine abuse on oral health: a cross-sectional study. BMC oral health. 2016; 16: 59

4. Arora A., Khattiri S, Ismail NM, Nagraj SK, dan Prashanti E. School dental screening programmes for oral health. Cochrane Database Syst Rev. 2017; 12(12).

5. Moreno-Quispe L.A, Espinoza-Espinoza LA, Bedon-Pajuelo LS, Guzmán-Avalos M. Dental caries in the peruvian police population. J Clin Exp Dent. 2018; 10(2): 134-8.

6. Vainionpaa R., Kirsi T, Paula P, Marja-Liisa $L$ dan Vuokko A. Erosive tooth wear and use of psychoactive substances among Finnish prisoners. BMC Oral Health. 2019;

\section{9: 97}

7. Al-Amin M. dan Juniati D. Klasifikasi Kelompok Umur Manusia Berdasarkan Ana-lisis Dimensi Fraktal Box Counting Dari Cit-ra Wajah Dengan Deteksi Tepi Canny. Jurnal IImiah Matematika. 2017; 2(6). ISSN 2301-9115

8. Murphy DA, Vivek S, Harrell L, Clague J, Dye BA, dan Belin TR. Methamphetamine users have increasead dental disease: a propensity score analy-sis. J Dent Res. 2016; 95(7): 814-21

9. Markonahally D, Gupta V dan Krishnappa P. Meth abuse and oral health. J Indian Assoc Public Health Dent. 2015; 13: 87-90.

10. Yazdani R, Hessari H, Rahmani S, dan Fard MJK. Oral and dental complications caused by methamphetamine use: $A$ review. J Craniomax Res. 2018; 5(2): 61-6.

11. Brown $C$, Krishnan $S$, Hursh $K, Y U M$, Johnson P, dan Page K. Dental disease prevalence among methamphetamine and heroin users in an urban setting: a pilot study. J Am Dent Assoc. 2012; 143: 992-1001.

12. Smit DA. Dan Sudeshni N. Oral health effects, brushing habits and management of methamphetamine users for the general dental practitioner. British Dental Journal. 2015; 218: 531-.6

13. Belin TR, Vivek S, Mooney LJ, Zigler CM, Murphy D, dan Rawson R. The relationship between methamphetamine use and increased dental disease. J Am Dent Assoc. 2010; 141 (3): 307-18 